\title{
ORIGINAL ARTICLE \\ The effect of FES-rowing training on cardiac structure and function: pilot studies in people with spinal cord injury
}

\author{
RS Gibbons ${ }^{1}$, CG Stock ${ }^{1}$, BJ Andrews ${ }^{2}$, A Gall $^{3}$ and RE Shave ${ }^{4}$
}

Study design: Two studies were conducted: Study-1 was cross-sectional; and Study-2 a longitudinal repeated measures design. Objectives: To examine the influence of functional electrical stimulation (FES) rowing training on cardiac structure and function in people with spinal cord injury (SCl).

Setting: A university sports science department and home-based FES-training.

Methods: Fourteen participants with C4-T10 SCI (American Spinal Injury Association Impairment Scale A or B) were recruited for the studies. Cardiac structure and function, and peak: oxygen uptake $\left(\mathrm{VO}_{2 \text { peak }}\right)$, power output $\left(\mathrm{PO}_{\text {peak }}\right)$ and heart rate $\left(\mathrm{HR}_{\text {peak }}\right)$, were compared between two FES-untrained groups (male $n=3$, female $n=3$ ) and an FES-trained group (male $n=3$ ) in Study-1 and longitudinally assessed in an FES-naive group (male $n=1$, female $n=4$ ) in Study-2. Main outcome measures left ventricular-

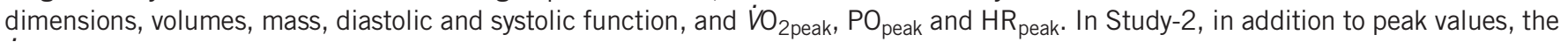
$\mathrm{VO}_{2}$ sustainable over $30 \mathrm{~min}$ and the related $\mathrm{PO}$ and $\mathrm{HR}$ were also assessed.

Results: Sedentary participants with chronic SCI had cardiac structure and function at the lower limits of non-SCI normal ranges. Individuals with chronic SCl who habitually FES-row have cardiac structure and function that more closely resemble non-SCI populations. A programme of FES-rowing training improved cardiac structure and function in previously FES-naive people.

Conclusion: FES-rowing training appears to be an effective stimulus for positive cardiac remodelling in people with SCI. Further work, with greater participant numbers, should investigate the impact of FES-rowing training on cardiac health in SCl.

Sponsorship: We thank the INSPIRE Foundation, UK, for funding these studies.

Spinal Cord (2016) 54, 822-829; doi:10.1038/sc.2015.228; published online 12 January 2016

\section{INTRODUCTION}

Imposed inactivity and impaired autonomic function result in marked physical deconditioning following spinal cord injury (SCI). ${ }^{1}$ This is related to a greater incidence of cardiovascular disease $(\mathrm{CVD})^{2}$ and increased mortality. ${ }^{3}$ Furthermore, the onset of CVD occurs earlier in SCI compared with non-SCI populations. ${ }^{4,5}$ Left ventricular (LV) diastolic dysfunction, secondary to inactivity-induced cardiac unloading, may indicate the earliest stages of CVD in people with SCI. ${ }^{6}$ Furthermore, diastolic dysfunction is closely related to an increased risk of CVD, especially in elderly and female populations. ${ }^{7}$ Although SCI athletes have reduced atherosclerosis when compared with sedentary SCI individuals, ${ }^{8}$ the influence of regular exercise training on cardiac structure and function in the non-athletic SCI population is inconclusive. $^{9-16}$

In the non-SCI population, there is evidence of a dose-response relationship between habitual activity levels and cardiovascular health, with the greatest benefits associated with higher intensities and volumes of physical activity. ${ }^{17}$ The American College of Sports Medicine (ACSM) guidelines for reduced CVD risk specify moderate-intensity ( 3-5.9 METs or $10.5-20.7 \mathrm{ml} \mathrm{kg}^{-1} \mathrm{~min}^{-1}$ ) aerobic training on $\geqslant 5$ days per week for a total of $\geqslant 150 \mathrm{~min}$, or vigorous-intensity ( $>6$ METs or $21 \mathrm{ml} \mathrm{kg}^{-1} \mathrm{~min}^{-1}$ ) training $\geqslant 3$ days per week for $\geqslant 75 \mathrm{~min}$, with a total exercise volume loading of $\geqslant 500-1000$ MET min per week. ${ }^{18}$ However, regular aerobic training in SCI relies predominantly on upper-body exercise. The small muscle mass involved in upper-body exercise limits the ability of people with SCI to sustain high levels of aerobic exercise. ${ }^{1}$ In an attempt to increase the aerobic training stimulus, exercise modalities that combine voluntary upper-limb exercise concurrent with functional electrical stimulation (FES)-assisted lower-limb exercise, specifically arm crank exercise (ACE) concurrent with FES-cycling (hybrid FES-cycling) and FES-rowing, have been studied. ${ }^{19-27}$ However, although hybrid FES-cycling has demonstrated significantly greater peak oxygen uptake $\left(\dot{V} \mathrm{O}_{2 \text { peak }}\right)$ compared with FES-cycling, $\left(1.49 \pm 0.14\right.$ vs $0.83 \pm 0.061 \mathrm{~min}^{-1}$ (Krauss et al. $\left.{ }^{21}\right)$ and $1.91 \pm 0.49$ versus $1.57 \pm 0.451 \mathrm{~min}^{-1}$ (Mutton et al. ${ }^{22}$ )), the ability to sustain steady-state aerobic exercise to the threshold level recommended by ACSM, using hybrid FES-cycling, is questionable $\left(1.69 \pm 0.531 \mathrm{~min}^{-1}\right.$ over 10-min). ${ }^{22}$ By comparison, previous studies have shown that a $\dot{V} \mathrm{O}_{2}$ of $2.171 \mathrm{~min}^{-1}\left(31.0 \mathrm{ml} \mathrm{kg}^{-1} \mathrm{~min}^{-1}\right)$ is sustainable for $30 \mathrm{~min}$ with FES-rowing. ${ }^{24}$ FES-rowing not only increases 'active' muscle mass but creates a lower-limb muscle pump, thus improving venous return. ${ }^{28}$ Rowing training is unique in that it involves components of aerobic endurance and muscular strength exercise and is associated

${ }^{1}$ Centre for Sports Medicine and Human Performance, College of Health and Life Sciences, Brunel University London, London, UK; ${ }^{2}$ Nuffield Department of Surgical Sciences, Oxford University, Oxford, UK; ${ }^{3}$ Royal National Orthopaedic Hospital, London, UK and ${ }^{4}$ Cardiff School of Sport, Cardiff Metropolitan University, Cardiff, UK

Correspondence: Dr RS Gibbons, Centre for Sports Medicine and Human Performance, College of Health and Life Sciences, Brunel University London, Kingston Lane, UB8 3PH London, UK.

E-mail: robin.gibbons@virgin.net

Received 20 February 2015; revised 27 September 2015; accepted 30 November 2015; published online 12 January 2016 
with significant elevations in blood pressure. Indeed, the spike in blood pressure observed at the start of each rowing stroke (the 'catch') has been implicated in the significant cardiac hypertrophy observed in elite oarsmen. ${ }^{29}$ Accordingly, it is possible that long-term FES-rowing training, where increased volume loading of the heart, and via the Frank-Starling relationship, increased SV, ${ }^{20}$ will elicit greater cardiac adaptation in people with SCI than observed in studies that have used upper-body exercise or FES-cycling. ${ }^{9,15,16}$ However, previous training studies employing FES-rowing have not examined cardiac structure and function in people with SCI. To test the hypothesis that FESrowing training improves cardiac structure and function in SCI, two studies were completed: Study-1 a cross-sectional comparison between sedentary individuals with long-term SCI and individuals habitually engaged in FES-rowing training; and Study-2 a longitudinal FES-rowing training study in a group of FES-naive participants.

\section{MATERIALS AND METHODS}

Study-1

Participants. A total of nine participants populated three study groups comprising a male $(n=3)$ and female $(n=3)$ FES-untrained (FES-UT) group and a third male $(n=3)$ FES-trained (FES-T) group (Table 1). Participants were aged between 26 and 56 years, at least 12 months post injury, with consultant-reported level and completeness of injury between cervical vertebrae 4 (C4) with an elbow flexion function and thoracic vertebrae 10 (T10). They were also neurologically stable with American Spinal Injury Association Impairment Scale A (complete motor and sensory) or B (complete motor incomplete sensory). Participants were otherwise healthy with no prior history of musculoskeletal complications and had not been prescribed medications that would affect the cardiac function. Brunel University Research Ethics Committee approved the study, and all participants gave written informed consent.

Table 1 Individual and group participant characteristics

\begin{tabular}{|c|c|c|c|c|c|c|}
\hline Participants & Sex & Injury & AIS & Aetiology & TPI (years) & Age (years) \\
\hline \multicolumn{7}{|l|}{ Study-1 } \\
\hline \multicolumn{7}{|l|}{ FES-UT } \\
\hline 1 & $\mathrm{~F}$ & C6 & $A$ & Transport & 17 & 34 \\
\hline 2 & $\mathrm{~F}$ & $\mathrm{C7}$ & B & Transport & 19 & 34 \\
\hline \multirow[t]{2}{*}{3} & $\mathrm{~F}$ & T10 & $A$ & Fall & 1 & 32 \\
\hline & & & & & $12 \pm 10$ & $33 \pm 1$ \\
\hline \multicolumn{7}{|l|}{ FES-UT } \\
\hline 4 & $M$ & $\mathrm{C} 4$ & $A$ & Sport & 7 & 23 \\
\hline 5 & $M$ & $\mathrm{~T} 6$ & $A$ & Transport & 13 & 50 \\
\hline \multirow[t]{2}{*}{6} & $M$ & T8 & $A$ & Sport & 14 & 41 \\
\hline & & & & & $11 \pm 4$ & $38 \pm 14$ \\
\hline \multicolumn{7}{|l|}{ FES-T } \\
\hline 7 & $M$ & $\mathrm{C} 6$ & $A$ & Transport & 5 & 26 \\
\hline 8 & M & T2 & $A$ & Fall & 5 & 45 \\
\hline \multirow[t]{2}{*}{9} & $M$ & $\mathrm{~T} 4$ & $A$ & Transport & 10 & 56 \\
\hline & & & & & $7 \pm 3$ & $42 \pm 15$ \\
\hline \multicolumn{7}{|l|}{ Study-2 } \\
\hline 1 & $M$ & $\mathrm{C} 4$ & $A$ & Sport & 7 & 24 \\
\hline 2 & $\mathrm{~F}$ & $\mathrm{C} 4$ & $A$ & Transport & 7 & 35 \\
\hline 3 & $\mathrm{~F}$ & $\mathrm{C} 6$ & $A$ & Transport & 18 & 35 \\
\hline 4 & $\mathrm{~F}$ & T6 & $A$ & Non-T & 1 & 33 \\
\hline \multirow[t]{2}{*}{5} & $\mathrm{~F}$ & $\mathrm{~T} 10$ & $A$ & Fall & 1.8 & 32 \\
\hline & & & & & $7 \pm 7$ & $32 \pm 5$ \\
\hline
\end{tabular}

Abbreviations: AIS, American Spinal Injury Association Impairment Scale ( $A=$ motor and sensory complete; $\mathrm{B}=$ motor complete sensory incomplete); $\mathrm{C}$, cervical; $\mathrm{F}$, female; FES-UT, functional electrical stimulation-untrained; FES-T, FES-trained; M, male; Non-T, non-traumatic injury; $\mathrm{T}$, thoracic; TPI, time post injury. Values reported are individual and group mean \pm s.d.
Test procedures. Participants attended the laboratory once and underwent a resting cardiac ultrasound assessment followed by an incremental ACE test (Lode Angio, Lode BV, Groningen, The Netherlands). Participants were instructed to arrive at the laboratory in a rested and fully hydrated state at least $2 \mathrm{~h}$ postprandial. They were also asked to avoid any strenuous exercise in the preceding $48 \mathrm{~h}$, along with caffeine for $12 \mathrm{~h}$ and alcohol for $24 \mathrm{~h}$. To avoid episodes of autonomic dysreflexia, participants were required to empty their bladder prior to testing. ${ }^{30}$

Arm crank incremental exercise tests. Incremental exercise test protocols have been previously described. ${ }^{27}$ Briefly, a 3-min rest period preceded a standardised warm-up of $5 \mathrm{~min}$ at a modest self-selected exercise intensity. Thereafter, 1 -min incremental stages were completed to the point of volitional exhaustion. The number of stages completed was closely related to the level of injury with a minimum of one and a maximum of eight stages being completed by the participants. Individual $\dot{V} \mathrm{O}_{2 \text { peak }}$ and relative $\dot{V} \mathrm{O}_{2 \text { peak }}$ values were assessed online breath-by-breath (Oxycon Pro, Jaeger, Hochberg, Germany). Standard ACSM test guidelines and recommendations were used to assess peak exercise responses. ${ }^{18}$

Resting cardiac structure and function. Participants transferred to a plinth and to optimise image acquisition were placed in a modified left lateral decubitus position (body raised $45^{\circ}$ to the horizontal) for $5 \mathrm{~min}$ prior to imaging. ${ }^{31}$ During echocardiographic imaging, participants were asked to pause their breathing at functional residual capacity while five consecutive cardiac cycles were recorded with a $1.5-4 \mathrm{MHz}$ phased-array transducer on a commercial ultrasound system (Vivid 7; GE Medical Systems, Horton, Norway). A threelead electrocardiogram recorded heart rate simultaneously with echocardiographic imaging.

LV structure and diastolic and systolic function were measured using a combination of conventional 2-D, M-Mode, Doppler and tissue Doppler ultrasound techniques. Briefly, 2-D and M-mode parasternal long axis images were used to measure LV dimensions and volumes during diastole and systole. To assess cardiac hypertrophy, ${ }^{32}$ relative wall thickness in diastole (RWTd), LV mass (LVM) and relative LVM were calculated as recommended by the European Society of Cardiology. ${ }^{33} \mathrm{LV}$ end-diastolic (EDV) and end-systolic volumes (ESV), stroke volume (SV) and ejection fraction (EF) were determined from apical 2- and 4-chamber images using Simpson's biplane method. ${ }^{33}$ Pulsed-wave Doppler was used at the mitral leaflet tips to assess LV inflow velocities during early (E) and late (A) diastole. ${ }^{33}$ Tissue Doppler imaging was applied to the septal wall at the level of the mitral annulus to assess myocardial tissue velocities in early (E') and late (A') diastole and systole ( $\left.\mathrm{S}^{\prime}\right){ }^{34}$ Myocardial wall relaxation was assessed by the $\mathrm{E}^{\prime} / \mathrm{A}^{\prime}$ ratio, ${ }^{35}$ and the $\mathrm{E} / \mathrm{E}^{\prime}$ ratio ${ }^{34}$ was used as a surrogate of LV filling pressures. Flow propagation velocity (FPV) was assessed from apical 4-chamber images according to the protocol of Nagueh et al. ${ }^{35}$ Cardiac output $(\dot{Q})$ was calculated as $\mathrm{SV} \times$ heart rate $(\mathrm{HR})$.

\section{Study-2}

For the longitudinal training study, 5 FES-naive participants with AIS A complete SCI were recruited. Although participants had no sacral sparing, all had partial sensory and motor innervation caudal to the level of injury within a zone of partial preservation..$^{36}$ Additional to the recruitment criteria detailed in Study-1, participants needed to be tolerant to and have no significant autonomic symptoms during an FES response test. ${ }^{30}$ This was assessed while demonstrating Medical Research Council (MRC), ${ }^{37}$ grade-1 or grade-2 FESactivated knee extension function, following recommended test protocols. ${ }^{38}$ Furthermore, volunteers were required to demonstrate MRC grade- 4 voluntary elbow flexion function. This was only possible in our participants with complete $\mathrm{C} 4$ tetraplegia due to partial motor innervation caudal to the level of injury. ${ }^{36}$ Study- 2 consisted of a progressive structured FES-training programme, which has been previously described. ${ }^{27}$ Briefly, weekly FES-training sessions were organised into two conditioning phases to increase quadriceps fatigue resistance and force-generating characteristics and a third intervention phase: Phase-1, FES-leg conditioning comprising alternate FES-activated knee extension exercise building to daily 60-min training sessions; Phase-2, FES-leg conditioning for 60-min alternated with interval FES-rowing training progressing to continuous FES-rowing for 30-min; and Phase-3, three FES-rowing 
Table 2 Study-1 individual male and female peak cardiorespiratory response to ACE incremental exercise test

\begin{tabular}{|c|c|c|c|}
\hline \multirow[t]{2}{*}{ Variables } & FES-UT & FES-UT & FES-T \\
\hline & Female & Male & Male \\
\hline \multicolumn{4}{|l|}{ Baseline (rest) } \\
\hline HR (beats $\min ^{-1}$ ) & $80 \pm 16$ & $73 \pm 14$ & $63 \pm 8$ \\
\hline $\mathrm{SBP}(\mathrm{mm} \mathrm{Hg})$ & $103 \pm 9$ & $110 \pm 13$ & $111 \pm 13$ \\
\hline $\mathrm{DBP}(\mathrm{mm} \mathrm{Hg})$ & $71 \pm 13$ & $73 \pm 10$ & $57 \pm 8$ \\
\hline $\mathrm{BM}(\mathrm{kg})$ & $54.3 \pm 0.6$ & $72.0 \pm 21.4$ & $74.0 \pm 6.6$ \\
\hline BMI $\left(\mathrm{kg} \mathrm{m}^{-2}\right)$ & $19.4 \pm 1.6$ & $22.6 \pm 5.9$ & $23.7 \pm 2.1$ \\
\hline \multicolumn{4}{|l|}{$A C E$ (peak) } \\
\hline IET increments (W) & $5 \pm 0$ & $6 \pm 4$ & $8 \pm 0$ \\
\hline $\mathrm{PO}(\mathrm{W})$ & $46.7 \pm 7.6$ & $80 \pm 65$ & $77 \pm 38$ \\
\hline$\dot{\mathrm{V}}_{2}\left(\mathrm{I} \mathrm{m^{-1 }}\right)$ & $0.80 \pm 0.08$ & $1.18 \pm 0.50$ & $1.35 \pm 0.50$ \\
\hline$\dot{\mathrm{V}}_{2}\left(\mathrm{~kg} \mathrm{~min}^{-1}\right)$ & $14.9 \pm 1.9$ & $15.7 \pm 3.1$ & $18.3 \pm 6.5$ \\
\hline HR (beats $\min ^{-1}$ ) & $150 \pm 32$ & $160 \pm 20$ & $130 \pm 30$ \\
\hline
\end{tabular}

Abbreviations: ACE, arm crank exercise; BM, body mass; BMI, BM index; DBP, diastolic blood pressure; FES-UT, functional electrical stimulation-untrained; FES-T, FES-trained; HR, heart rate; IET, incremental exercise test; PO, power output; SBP, systolic blood pressure; $\mathrm{VO}_{2}$, oxygen uptake.

Values reported are group mean \pm s.d. sessions at an intensity equivalent to $60-80 \%$ of an individual's $\dot{V} \mathrm{O}_{2 \text { peak }}$ and four FES-leg conditioning sessions every week for 8 weeks. Progression from Phase- 1 was dependent on the ability to FES-leg condition for $60 \mathrm{~min}$ and from Phase-2 the ability to continuously row for $30 \mathrm{~min}$. Phase- 1 and Phase- 2 therefore required varying volumes of training that was independent of the level of injury before starting Phase-3.

During FES-rowing training, people with paraplegia control the stimulator channel selection by a momentary-action switch mounted on the rowing handle. ${ }^{24}$ As previously reported, the weak or absent handgrip strength in tetraplegia can be circumvented by training carers to operate the momentaryaction switch in synchrony with the rower's voluntary arm flexion movements. ${ }^{27}$ Thus, providing participants had MRC grade-4 elbow flexion function, individuals with tetraplegia were able to condition their lower-limbs during FES-rowing training to the same level as their counterparts with paraplegia. Since our previous study, ${ }^{27}$ two important equipment modifications were made to increase lower-limb work: (i) during FES-rowing training/testing, participants were instructed to gradually increase the quadriceps stimulation current up to the maximum available $115 \mathrm{~mA}$ by the end of the 5 -min warmup; and (ii) the spring-loaded end-stops described in, Hettinga and Andrews ${ }^{24}$ were removed prior to Phase-3 once participants had sufficient upper-limb strength and dexterity to control the rowing action unassisted. This stopped the participants from ricocheting back and forth between the end-stops, and thus all movement along the rowing ergometer track was dependent upon muscular work.

Table 3 Study-1 individual cardiac variables for males and females with chronic tetraplegia and paraplegia compared with normal non-SCI ranges

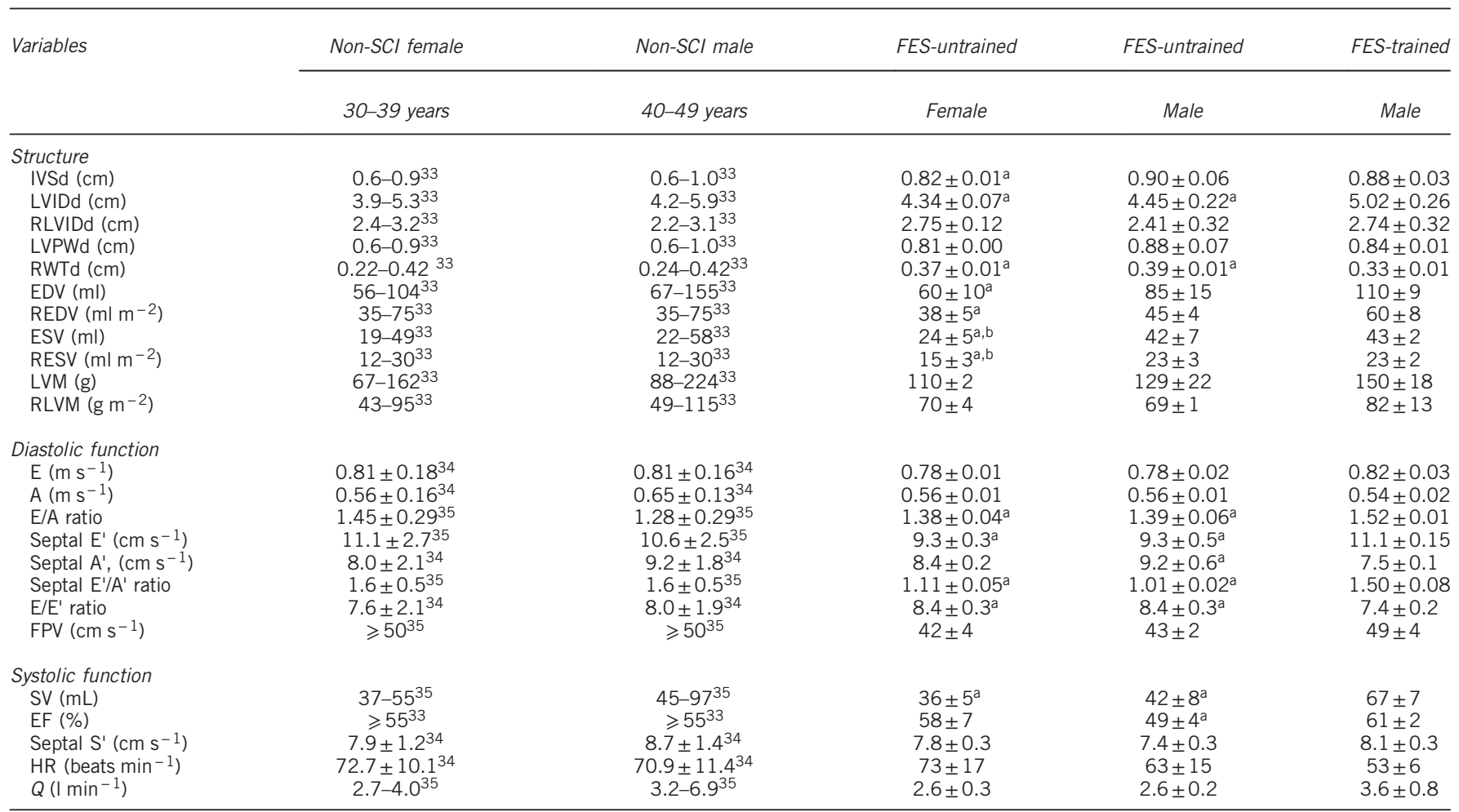

Abbreviations: A, late LV relaxation diastole; E, early LV relaxation diastole; E/A, ratio early to late diastole; EDV, end-diastolic volume; E/E', ratio early LV relaxation diastole to early septal myocardial tissue velocity diastole; EF, ejection fraction; ESV, end-systolic volume; FES-UT, functional electrical stimulation-untrained; FES-T, FES-trained; FPV, flow propagation velocity; HR, heart rate; IVSd, inter-ventricular septum diastole; LVIDd, left ventricular internal diameter diastole; LVM, left ventricular mass; LVPWd, LV posterior wall diastole; non-SCI, non spinal cord injured; RLVIDd, relative LVIDd; RWTd, relative wall thickness diastole; REDV, relative EDV; RESV, relative ESV; RLVM, relative LVM; Septal E', early septal myocardial tissue velocity diastole; Septal A' late septal myocardial tissue velocity diastole; Septal E'/A', ratio early to late septal myocardial tissue velocity diastole; SV, stroke volume; Septal S', septal myocardial tissue velocity systole; $\dot{Q}$, cardiac output.

Values reported are group means \pm s.d.

References for normal ranges provided in the table.

asignificant compared with FES-T male.

bSignificant compared with FES-UT male. 
Cardiac ultrasound assessments and ACE incremental exercise tests as outlined above were completed prior to Phase-1, on completion of Phase-2 and on completion of Phase-3. In addition, on completion of Phase- 2 and Phase-3, participants completed an FES-rowing incremental exercise test as previously described. ${ }^{27}$ The first test was used to prescribe FES-rowing training intensity during Phase-3 (60-80\% of peak exercise responses) and the second to examine training-induced improvements in $\dot{V} \mathrm{O}_{2 \text { peak. }}$

Analysis. Data from Study-1 and Study-2 were analysed using a simple analysis of variance and a repeated measures analysis of variance, respectively, using Prism 6 software (GraphPad Software, La Jolla, CA, USA). Alpha was set at $P<0.05$. For comparison, cardiac data are presented alongside previously reported values for non-SCI individuals. ${ }^{33-35}$

\section{RESULTS}

Study-1

Peak cardiorespiratory exercise response. When comparing participants of similar age, sex and level of injury, individual $\dot{V} \mathrm{O}_{2 \text { peak }}$ and relative $\dot{V} \mathrm{O}_{2 \text { peak }}$ values in response to ACE showed marked inter-individual variability and were not significantly different between the FES-UT and FES-T groups (Table 2).

Resting cardiac structure and function. LV structure and function in all participants were comparable or fell within previously reported values for non-SCI individuals, regardless of training status (Table 3). However, in the two FES-UT groups, LVIDd, EDV, relative EDV (REDV), LVM, E/A, FPV, SV and $\dot{Q}$ were at the lower end and RWTd and $E / E$ ' were at the higher end of previously reported values for non-SCI individuals. ${ }^{33-35}$ In addition, LVIDd, EDV, REDV, ESV and relative ESV (RESV) were lower in FES-UT females, and LVIDd was lower in FES-UT males, compared to FES-T. Furthermore, RWTd was higher in FES-UT compared to FES-T $(P<0.05)$ (Table 3). Analysis of the diastolic function revealed E/A, E' and E'/A' to be lower in FES-UT compared with FES-T and E/E' higher $(P<0.05)$. Systolic function as characterised by SV was significantly lower in FES-UT compared to FES-T $(P<0.05)$, and resting HR tended to be higher and $\dot{Q}$ lower in FES-UT compared to FES-T (Table 3 ). There were no statistically significant differences in blood pressure between the groups (Table 2).
Study-2

Peak cardiorespiratory exercise response pre-post FES-rowing training. Although a number of participants showed some level of autonomic dysreflexia during the FES response test, it was not sufficient to limit stimulation intensity. In addition, there were no medical complications attributed to FES-rowing training, and all participants completed the full training programme. As shown previously, ${ }^{27}$ individuals required differing volumes of training to reach the end of Phase-1 and Phase-2. However, 100\% training compliance was maintained throughout the 8-week period of Phase-3. Individual ACE $\dot{V} \mathrm{O}_{2 \text { peak }}$ and peak power output $\left(\mathrm{PO}_{\text {peak }}\right)$ increased over the course of the training programme, and FES-rowing $\dot{V} \mathrm{O}_{2 \text { peak }}$ and $\mathrm{PO}_{\text {peak }}$ increased during Phase-3. Importantly, by the end of Phase-3 training, the $\dot{V O}_{2}$ that was sustainable during the 30-min FES-row was between 65 and $81 \%$ in participants with tetraplegia, and between 85 and $95 \%$ in individuals with paraplegia, of the vigorous-intensity $\left(21 \mathrm{ml} \mathrm{kg}^{-1} \mathrm{~min}^{-1}\right)$ threshold suggested by ACSM. ${ }^{18}$

Resting cardiac structure and function. Significant increases in LVIDd, EDV, REDV, ESV and LVM were observed across the training programme, whereas RWTd decreased $(P<0.05)$ (Table 5 and Figure 1). Diastolic function, specifically E, E/A, E', E'/A' and FPV values, increased across the training programme and $\mathrm{A}, \mathrm{A}^{\prime}$ and $\mathrm{E} / \mathrm{E}^{\prime}$ decreased $(P<0.05)$ (Table 5 and Figures 2 and 3). Systolic function, as measured by SV, EF and $\dot{Q}$, also increased with training $(P<0.05)$, but $S$ ' did not significantly change (Table 5$)$. There was a decrease in resting $\mathrm{HR}$ and an increase in resting blood pressure during the training programme, although not statistically significant.

\section{DISCUSSION}

\section{Main findings}

The aim of the present studies was to examine the influence of FES-rowing on cardiac structure and function in people with SCI. The main findings were (i) sedentary people with chronic SCI appear to have cardiac structure and function at the lower end of previously reported values for non-SCI people, ${ }^{33-35}$ (ii) people with SCI who habitually train with FES-rowing have cardiac structure and function that more closely resemble non-SCI people and (iii) a programme of FES-rowing training

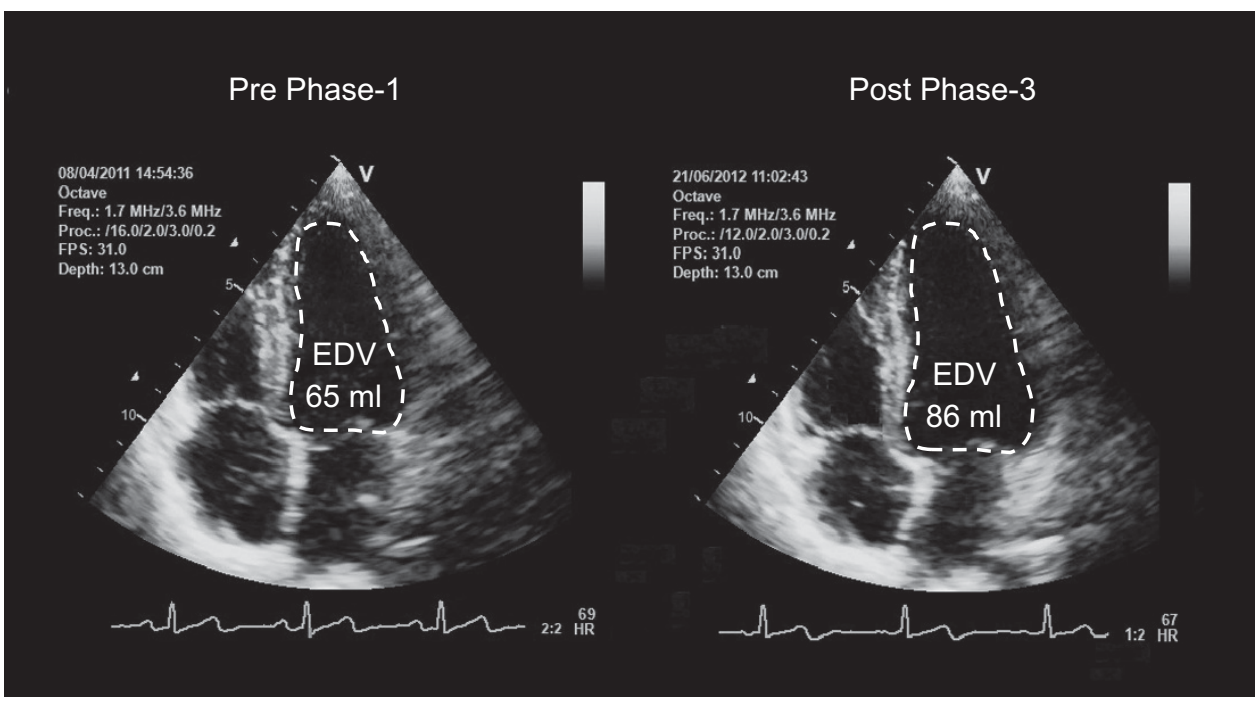

Figure 1 Representative images from participant 5 showing resting end-diastolic volume (EDV) pre Phase-1 and post Phase-3. 


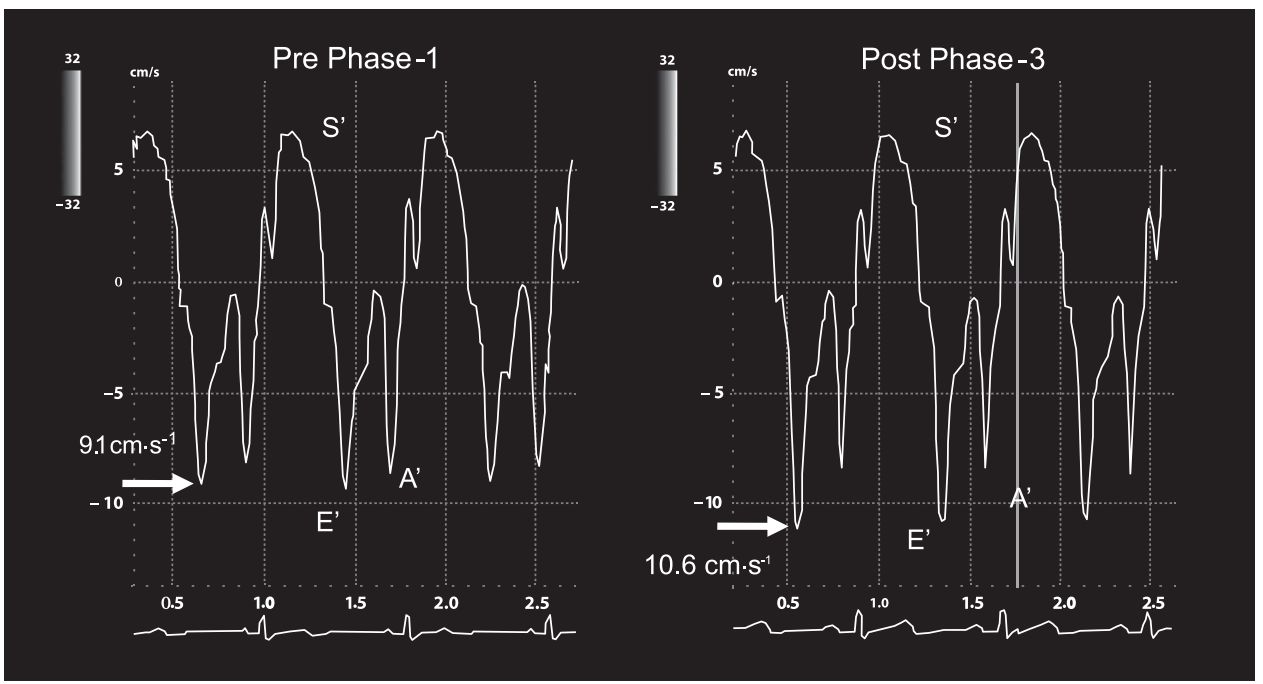

Figure 2 Representative images from participant 3 showing resting myocardial tissue velocities during systole ( $\left.S^{\prime}\right)$, and early ( $\left.E^{\prime}\right)$ and late ( $\left.A^{\prime}\right)$ diastole pre Phase-1 and post Phase-3.
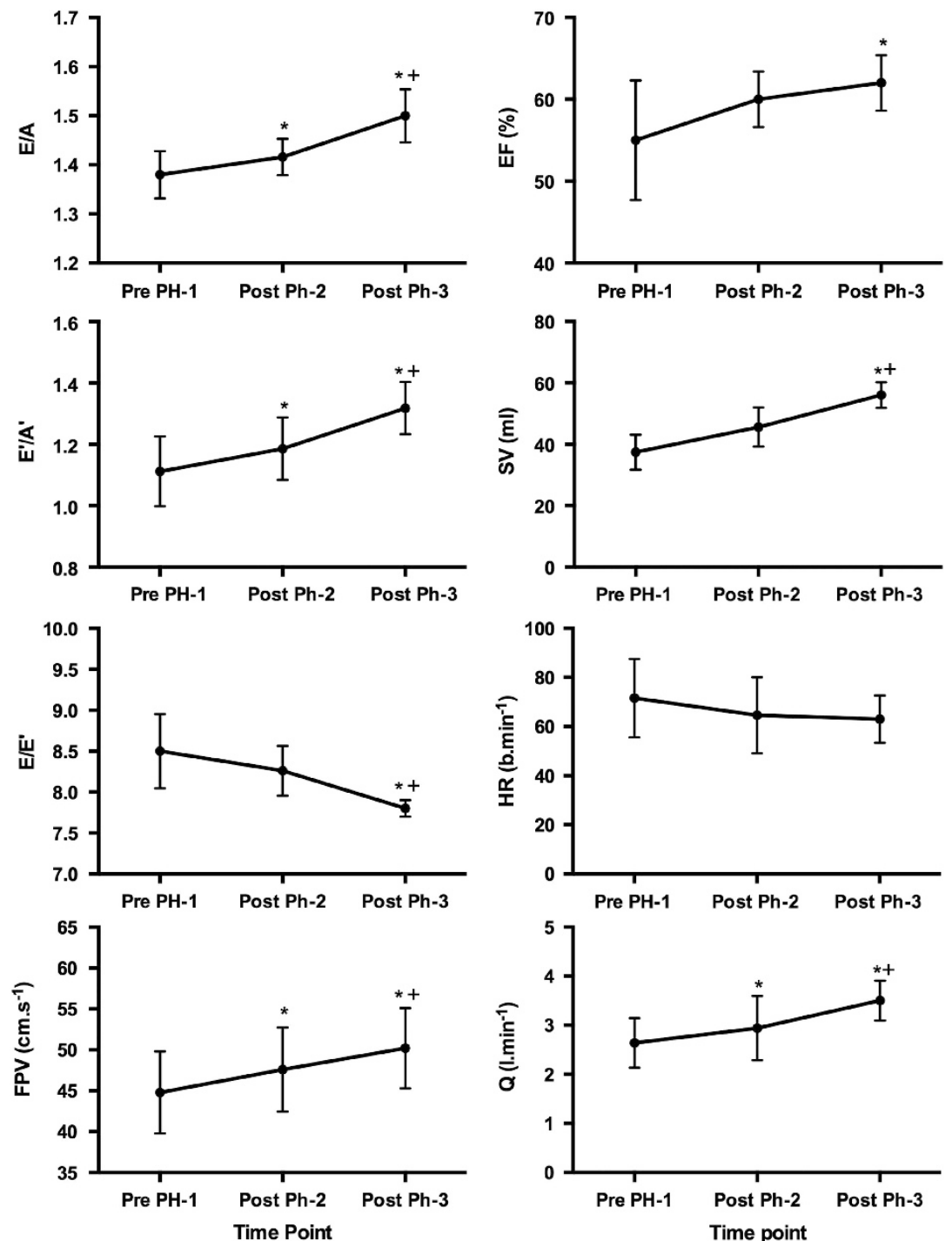

Figure 3 Group diastolic and systolic function changes during Study-2. Values indicated are group means \pm s.d. Left column, diastolic function; right column, systolic function. *Significant compared with pre Phase- $1 ;^{+}$significant compared with post Phase-2. 
improves cardiac structure and function in previously FES-naive people.

\section{Cardiac structure and function in chronic SCI}

The changes in diastolic filling associated with long-term physical inactivity have been shown to be a specific risk factor in the development of diastolic dysfunction ${ }^{6}$ and heart failure in the general population. ${ }^{39,40}$ Similar to previous studies, ${ }^{13,14}$ we show that sedentary SCI is associated with cardiac structure and diastolic function at the lower end of previously reported values for non-SCI individuals. ${ }^{33-35}$ The smaller LV chamber size seen in FES-UT may be an adaptive response of the myocardium to maintain wall stress, ${ }^{41}$ in response to reduced blood volume $e^{42}$ and increased lower-limb blood pooling from impaired sympathetic vasoconstrictor function. ${ }^{43}$ Lower blood pressure, especially in tetraplegia ${ }^{44}$ and female populations, ${ }^{45}$ may be an additional influence on LV chamber size in people with SCI. The higher RWTd seen in FES-UT compared with FES-T may indicate a pattern of cardiac hypertrophy in response to circulatory hypertension. ${ }^{32}$ The mechanisms that underpin the reduction in the diastolic function in SCI appear complex and require further study. For example, de Rossi et al., ${ }^{14}$ showed that a degraded diastolic function was independent of the level of injury, time post injury and haemodynamic, metabolic and inflammatory variables. Regardless of the specific mechanisms, any intervention that improves cardiac structure and function in SCI is considered highly desirable. $^{1}$

\section{Cardiac response to FES-rowing training}

Previous studies using upper-body exercise training or FES-cycling have shown little cardiac adaptation in people with SCI. ${ }^{9,15,16}$ However, on the basis of oxygen uptake, exercise intensity and volume are limited in these modalities, ${ }^{25,46}$ falling below presently recommended threshold guidelines. ${ }^{18}$ In Study-2, we demonstrate that individuals with complete SCI can achieve steady-state $\dot{V} \mathrm{O}_{2}$ values during 30-min FES-rowing training sessions (Table 4) that approach the vigorous-intensity threshold recommendations, with accumulated training volumes that fulfil the recommended guidelines. ${ }^{18}$ The present FES-rowing training may, therefore, provide sufficient exercise stimulus to result in cardiac adaptation, although the precise mechanism behind LV remodelling is unclear. FES-rowing exercise, where 'active' muscle mass is increased, concomitant with a lowerlimb muscle pump in synchrony with an upper-limb rowing action, likely provides increased volume loading of the heart. ${ }^{20}$ Accordingly, increased volume loading will improve SV and cardiac output through the Frank-Starling mechanism. ${ }^{20}$ In addition, the improvement in RWTd observed in Study-2 (Table 5) resembles a pattern of volume overload commonly observed in aerobically trained non-SCI individuals with a preserved autonomic function. ${ }^{47}$ Indeed, in line with previous findings, ${ }^{27}$ peak HR responses to FES-rowing were elevated compared with exercise-induced $\mathrm{HR}_{\text {peak }}$ typically observed in tetraplegia. ${ }^{48}$ This observation, despite cervical cord damage, appears to reflect an element of preserved sympathetic control. ${ }^{12}$ Collectively, these mechanisms may help explain the improvement in cardiac structure and function seen in the present studies, albeit in only five participants. These findings, therefore, require further investigation with greater participant numbers before they can be confirmed.

\section{Conclusions and study limitations}

The small numbers and very large variation in participant characteristics preclude definitive statements on the effect of FES-rowing on
Table 4 Study-2 individual male and female cardiorespiratory response to $\mathrm{ACE}$ and $\mathrm{FES}$-rowing incremental exercise tests

\begin{tabular}{|c|c|c|c|}
\hline Variables & Pre Phase-1 & Post Phase-2 & Post Phase-3 \\
\hline \multicolumn{4}{|l|}{ Baseline (rest) } \\
\hline HR (beats $\min ^{-1}$ ) & $86 \pm 11$ & $76 \pm 7$ & $73 \pm 2$ \\
\hline $\mathrm{SBP}(\mathrm{mm} \mathrm{Hg})$ & $98 \pm 14$ & $110 \pm 5$ & $113 \pm 6$ \\
\hline $\mathrm{DBP}(\mathrm{mm} \mathrm{Hg})$ & $69 \pm 10$ & $75 \pm 6$ & $71 \pm 6$ \\
\hline $\mathrm{BM}(\mathrm{kg})$ & $51.8 \pm 2.8$ & $54.4 \pm 3.0$ & $54.4 \pm 3.0$ \\
\hline BMI $\left(\mathrm{kg} \mathrm{m}^{-2}\right)$ & $17.8 \pm 2.3$ & $18.7 \pm 2.1$ & $18.7 \pm 2.1$ \\
\hline \multicolumn{4}{|l|}{$A C E$ (peak) } \\
\hline IET increments (W) & $4 \pm 2$ & $4 \pm 2$ & $4 \pm 2$ \\
\hline $\mathrm{PO}(\mathrm{W})$ & $33.6 \pm 24.4$ & $38.4 \pm 26.1$ & $40.4 \pm 27.8$ \\
\hline$\dot{\mathrm{V}}_{2}\left(\mathrm{Im}^{-1}\right)$ & $0.73 \pm 0.23$ & $0.82 \pm 0.27^{a}$ & $0.87 \pm 0.30^{a}$ \\
\hline$\dot{\mathrm{V}}_{2}\left(\mathrm{~kg} \mathrm{~min}^{-1}\right)$ & $13.8 \pm 3.9$ & $15.0 \pm 4.4$ & $16.0 \pm 5.1$ \\
\hline HR (beats $\min ^{-1}$ ) & $145 \pm 35$ & $143 \pm 29$ & $150 \pm 25$ \\
\hline \multicolumn{4}{|l|}{ FES-R (peak) } \\
\hline IET increments (W) & & $4 \pm 2$ & $4 \pm 2$ \\
\hline $\mathrm{PO}(\mathrm{W})$ & & $17.6 \pm 11.6$ & $22.4 \pm 12.9^{b}$ \\
\hline$\dot{\mathrm{V}}_{2}\left(\mathrm{I} \mathrm{m}^{-1}\right)$ & & $0.97 \pm 0.22$ & $1.08 \pm 0.26^{b}$ \\
\hline$\dot{\mathrm{V}} \mathrm{O}_{2}\left(\mathrm{~kg} \mathrm{~min}^{-1}\right)$ & & $17.8 \pm 3.5$ & $19.7 \pm 4.1^{b}$ \\
\hline HR (beats $\min ^{-1}$ ) & & $151 \pm 7$ & $163 \pm 3^{b}$ \\
\hline \multicolumn{4}{|l|}{ FES-R (sustainable) } \\
\hline PO (W) & & $15 \pm 10$ & $18 \pm 10^{\mathrm{b}}$ \\
\hline$\dot{\mathrm{V}} \mathrm{O}_{2}\left(\mathrm{I} \mathrm{m}^{-1}\right)$ & & $0.82 \pm 0.15$ & $0.90 \pm 0.16$ \\
\hline$\dot{\mathrm{V}} \mathrm{O}_{2}\left(\mathrm{~kg} \mathrm{~min}^{-1}\right)$ & & $15.1 \pm 2.5$ & $16.7 \pm 2.5^{b}$ \\
\hline MET & & $4.31 \pm 0.71$ & $4.76 \pm 0.71$ \\
\hline MET (min per week) & & $388 \pm 64$ & $429 \pm 64$ \\
\hline HR (beats min $^{-1}$ ) & & $137 \pm 7$ & $148 \pm 10$ \\
\hline
\end{tabular}

Abbreviations: ACE, arm crank exercise; BM, body mass; BMI, body mass index; DBP, diastolic blood pressure; FES-R, functional electrical stimulation rowing; HR, heart rate; IET, incremental exercise test; MET, metabolic equivalent; PO, power output; SBP, systolic blood pressure; $\mathrm{VO}_{2}$, oxygen uptake.

Values reported are group means \pm s.d.

Sustainable is defined as the PO or $\mathrm{VO}_{2}$ that can be maintained over a 30-min FES-rowing training session.

asignificant compared with pre Phase-1.

bSignificant compared with post Phase-2.

cardiovascular health in SCI. Notwithstanding, the improvements in cardiac structure and function observed in these studies provide evidence of potential cardiovascular benefits following FES-rowing training from a diverse group of individuals with SCI. Furthermore, as the full programme of FES-training in Study-2 was only 8-week duration (Phase-3), it is possible that cardiac structure and function will continue to improve as FES-rowing training continues. ${ }^{27}$ It is also important to note that individuals with SCI are typically faced with barriers to regular exercise above those experienced by the general population. ${ }^{1}$ This is especially so where limited availability and highcost specialist FES-training equipment is concerned. This barrier was circumvented by ethical approval for home-based FES-training. The findings in these studies, therefore, must be taken with caution, as they are based on achieving a very high training compliance. Future studies that investigate the impact of increasing the number of FES-channels, and therefore the activation of additional paralysed musculature, on metabolism, blood flow and cardiac structure and function, in a larger group of people with SCI, are recommended.

\section{DATA ARCHIVING}

There were no data to deposit. 
Table 5 Study-2 individual cardiac variables for male and females with chronic tetraplegia and paraplegia compared with normal non-SCl ranges

\begin{tabular}{|c|c|c|c|}
\hline Variables & Pre Phase-1 & Post Phase-2 & Post Phase-3 \\
\hline \multicolumn{4}{|l|}{ Structure } \\
\hline IVSd (cm) & $0.83 \pm 0.00$ & $0.82 \pm 0.01$ & $0.82 \pm 0.00$ \\
\hline LVIDd (cm) & $4.34 \pm 0.13$ & $4.42 \pm 0.10^{a}$ & $4.56 \pm 0.05^{a, b}$ \\
\hline RLVIDd (cm) & $2.77 \pm 0.08$ & $2.77 \pm 0.10$ & $2.84 \pm 0.09$ \\
\hline LVPWd (cm) & $0.80 \pm 0.01$ & $0.80 \pm 0.01$ & $0.80 \pm 0.00$ \\
\hline RWTd (cm) & $0.37 \pm 0.01$ & $0.36 \pm 0.01^{a}$ & $0.35 \pm 0.01^{a, b}$ \\
\hline EDV $(\mathrm{ml})$ & $65 \pm 8$ & $76 \pm 10^{a}$ & $91 \pm 9^{a, b}$ \\
\hline $\operatorname{REDV}\left(\mathrm{ml} \mathrm{m}^{-2}\right)$ & $42 \pm 5$ & $48 \pm 6^{a}$ & $57 \pm 7^{a, b}$ \\
\hline ESV (ml) & $28 \pm 5$ & $30 \pm 4$ & $35 \pm 6^{a}$ \\
\hline $\operatorname{RESV}\left(\mathrm{ml} \mathrm{m}^{-2}\right)$ & $18 \pm 4$ & $19 \pm 3$ & $22 \pm 5$ \\
\hline LVM (g) & $110 \pm 6$ & $113 \pm 5^{a}$ & $118 \pm 2^{a, b}$ \\
\hline RLVM $\left(\mathrm{g} \mathrm{m}^{-2}\right)$ & $70 \pm 3$ & $71 \pm 3$ & $73 \pm 2$ \\
\hline \multicolumn{4}{|l|}{ Diastolic function } \\
\hline$E\left(\mathrm{~m} \mathrm{~s}^{-1}\right)$ & $0.78 \pm 0.02$ & $0.80 \pm 0.02^{a}$ & $0.82 \pm 0.01^{a, b}$ \\
\hline$A\left(m^{-1}\right)$ & $0.57 \pm 0.00$ & $0.56 \pm 0.00$ & $0.55 \pm 0.01^{a}$ \\
\hline Septal $E^{\prime}\left(\mathrm{cm} \mathrm{s}^{-1}\right)$ & $9.2 \pm 0.7$ & $9.7 \pm 0.6^{a}$ & $10.5 \pm 0.3^{a, b}$ \\
\hline Septal $A^{\prime},\left(\mathrm{cm} \mathrm{s}^{-1}\right)$ & $8.3 \pm 0.2$ & $8.2 \pm 0.2$ & $8.0 \pm 0.32^{a, b}$ \\
\hline \multicolumn{4}{|l|}{ Systolic function } \\
\hline Septal S' $\left(\mathrm{cm} \mathrm{s}^{-1}\right)$ & $7.9 \pm 2$ & $7.9 \pm 0.2$ & $8.0 \pm 0.1$ \\
\hline \multicolumn{4}{|c|}{$\begin{array}{l}\text { Abbreviations: A, late LV relaxation diastole; E, early LV relaxation diastole; EDV, end-diastolic } \\
\text { volume; ESV, end-systolic volume; IVSd, inter-ventricular septum diastole; LVIDd, left ventricular } \\
\text { internal diameter diastole; LVM, left ventricular mass; LVPWd, LV posterior wall diastole; REDV, } \\
\text { relative EDV; RESV, relative ESV; RLVM, relative LVM; RWTd, relative wall thickness diastole; } \\
\text { Septal A', late septal myocardial tissue velocity diastole; Septal E', early septal myocardial } \\
\text { tissue velocity diastole; Septal S', septal myocardial tissue velocity systole; non-SCl, non spinal } \\
\text { cord injured. } \\
\text { Values reported are group means } \pm \text { s.d. } \\
\text { aSignificant compared with Pre Phase-1. } \\
\text { bSignificant compared with Post Phase-2. }\end{array}$} \\
\hline
\end{tabular}

\section{CONFLICT OF INTEREST}

The authors declare no conflict of interest.

1 Nash MS. Exercise as a health-promoting activity following spinal cord injury. J Neurol Phys Ther 2005; 29: 103-106.

2 Cowan RE, Nash MS. Cardiovascular disease, $\mathrm{SCl}$ and exercise: unique risks and focused countermeasures. Disabil Rehabil 2010; 32: 2228-2236.

3 Garshick E, Kelley A, Cohen SA, Garrison A, Tun CG, Gagnon D et al. A prospective assessment of mortality in chronic spinal cord injury. Spinal Cord 2005; 43: 408-416.

4 Myres J, Lee M, Kiratli J. Cardiovascular disease in spinal cord injury: an overview of prevalence, risk, evaluation, and management. Am J Phys Med Rehabil 2007; 86: $142-152$.

5 Bauman WA, Spungen AM. Coronary heart disease in individuals with spinal cord injury: assessment of risk factors. Spinal Cord 2008; 46: 466-476.

6 Perhonen MA, Franco F, Lane LD, Buckey JC, Blomqvist CG, Zerwekh JE et al. Cardiac atrophy after bed rest and spaceflight. J App/ Physiol 2001; 91: 645-653.

7 Paulus WJ, Tschope C, Sanderson JE, Rusconi C, Flachskampf FA, Rademakers FE et al. How to diagnose diastolic heart failure: a consensus statement on the diagnosis of heart failure with normal left ventricular ejection fraction by the Heart Failure and Echocardiography Associations of the European Society of Cardiology. Eur Heart J 2007; 28: 2539-2550.

8 Matos-Souza JR, Silva AA, Campos LF, Goulart D, Schreiber R, de Rossi G et al. Physical activity is associated with improved subclinical atherosclerosis in spinal cord injury subjects independent of variation in traditional risk factors. Int J Cardiol 2013; 167: 592-593

9 Gates PE, Campbell IG, George KP. Absence of training-specific cardiac adaptation in paraplegic athletes. Med Sci Sports Exerc 2002; 34: 1699-1704.

10 Maggioni MA, Ferratini M, Pezzano A, Heyman JE, Agnello L, Veicsteinas A et al. Heart adaptations to long-term aerobic training in paraplegic subjects: an echocardiographic study. Spinal Cord 2012; 50: 538-542.

11 Schumacher YO, Ruthardt S, Schmidt M, Ahlgrim C, Roecker K, Pottgiesser T. Total haemoglobin mass but not cardiac volume adapts to long-term endurance exercise in highly trained spinal cord injured athletes. Eur J App/ Physiol 2009; 105: 779-785.
12 West CR, Romer LM, Krassioukov A. Autonomic function and exercise performance in elite athletes with cervical spinal cord injury. Med Sci Sports Exerc 2012; 45: 261-267.

13 Matos-Souza JR, Pithon KR, Oliveira RTD, Teo FH, Blotta MHSL, Cliquet A Jr et al. Altered left ventricular diastolic function in subjects with spinal cord injury. Spinal Cord 2011; 49: 65-69.

14 de Rossi G, Matos-Souza JR, Costa E, Silva AD, Campos LF, Santos LG et al. Physical activity and improved diastolic function in spinal cord-injured subjects. Med Sci Sports Exerc 2014; 46: 887-892.

15 Danopulos D, Kezdi P, Stanley EL. Changes in cardiovascular circulatory dynamics after a twelve week active bicycle rehabilitation in young tetraplegics. J Neurol Orthop Med Surg 1986; 7: 179-184.

16 Nash MS, Bilsker S, Marcillo AE, Isaac SM, Botelho LA, John Klose K et al. Reversal of adaptive left ventricular atrophy following electrically-stimulated exercise training in human tetraplegics. Paraplegia 1991; 29: 590-599.

17 Garber CE, Blissmer B, Deschenes MR, Franklin BA, Lamonte MJ, Lee IM et al. American College of Sports Medicine. American College of Sports Medicine position stand. Quantity and quality of exercise for developing and maintaining cardiorespiratory, musculoskeletal, and neuromotor fitness in apparently healthy adults: guidance for prescribing exercise. Med Sci Sports Exerc 2011; 43: 1334-1359.

18 ACSM Guidelines for Exercise Testing and Prescription. American College of Sports Medicine. 9th edn; Lippincott Williams \& Wilkins, Indianapolis, IN, USA, 2013.

19 Hooker SP, Figoni SF, Rodgers MM, Glaser RM, Mathews T, Suryaprasad AG et al. Metabolic and hemodynamic response to concurrent voluntary arm crank and electrical stimulation leg cycle exercise in quadriplegics. J Rehabil Res Dev 1992; 29: 1-11.

20 Laskin JJ, Ashley EA, Olenik LM, Burnham R, Cumming DC, Steadward RD et al. Electrical stimulation-assisted rowing exercise in spinal cord injured people: a pilot study. Paraplegia 1993; 31: 534-541.

21 Krauss JC, Robergs RA, Depaepe JL, Kopriva LM, Aisenbury JA, Anderson MA et al. Effects of electrical stimulation and upper body training after spinel cord injury. Med Sci Sports Exerc 1993; 25: 1054-1061.

22 Mutton DL, Scremin AME, Barstow TJ, Scott MD, Kunkel CF, Cagle TG. Physiologic responses during functional electrical stimulation leg cycling and hybrid exercise in spinal cord injured subjects. Arch Phys Med Rehabil 1997; 78: 712-718.

23 Wheeler GD, Andrews GJ, Lederer R, Davoodi R, Natho K, Weiss C et al. Function electrical stimulation-assisted rowing: increasing cardiovascular fitness through functional electrical stimulation rowing training in persons with spinal cord injury. Arch Phys Med Rehabil 2002; 83: 1093-1099.

24 Hettinga DM, Andrews BJ. The feasibility of functional electrical stimulation indoor rowing for high-energy training and sport. Neuromodulation 2007; 10: 291-297.

25 Verellen J, Vanlandewijck Y, Andrews GJ, Wheeler GD. Cardiorespiratory responses during arm ergometry, functional electrical stimulation cycling, and two hybrid exercise conditions in spinal cord injured. Disabil Rehabil Assist Technol 2007; 2: 127-132.

26 Taylor JA, Picard G, Widrick JJ. Aerobic capacity with hybrid FES rowing in spinal cord injury: comparison with arms-only exercise and preliminary findings with regular training. PM R 2011; 3: 817-824.

27 Gibbons RS, Shave RE, Gall A, Andrews BJ. FES-rowing in tetraplegia: a preliminary report. Spinal Cord 2014; 52: 880-886.

28 Ragnarsson KT, Pollack S, O'Daniel W Jr, Edgar R, Petrofsky J, Nash MS. Clinical evaluation of computerized functional electrical stimulation after spinal cord injury: a multicentre pilot study. Arch Phys Med Rehabil 1988; 69: 672-677.

29 Secher NH. Physiological and biomechanical aspects of rowing. Implications for training. Sports Med 1993; 15: 24-42.

30 Milligan J, Lee J, McMillan C. Autonomic dysreflexia: Recognising a common serious condition in patients with spinal cord injury. Can Far Physician 2012; 58: 831-835.

31 Houghton AR. Making sense of Echocardiography. Hodder Arnold: : London, 2009.

32 Ganau A, Devereux B, Roman MJ, De Simone G, Pickering TG, Saba PS et al. Patterns of left ventricular hypertrophy and geometric remodeling in essential hypertension. J Am Coll Cardiol 1992; 19: 1550-1558.

33 Lang RM, Bierig M, Devereux RB, Flachskampf FA, Foster E, Pellikka PA et al. Recommendations for chamber quantification. Eur J Echocardiography 2006; 7: 79-108.

34 Innelli P, Sanchez R, Marra F, Esposito R, Galderisi M. The impact of aging on left ventricular longitudinal function in healthy subjects: a pulsed tissue Doppler study. Eur J Echocardiogr 2008; 9: 241-249.

35 Nagueh SF, Appleton CP, Gillebert TC, Marino PN, Oh JK, Smiseth OA et al. Recommendations for the evaluation of left ventricular diastolic function by echocardiography. Eur J Echocardiogr 2009; 10: 165-193.

36 Kirshblum SC, Burns SP, Biering-Sorensen F, Donovan W, Graves DE, Jha A et al. International standards for neurological classification of spinal cord injury. J Spinal Cord Med 2011; 34: 535-546.

37 James MA. Use of the Medical Research Council muscle strength grading system in the upper extremity. J Hand Surg Am 2007; 32: 154-156.

38 Taylor P. The Odstock 4 Channel Stimulator: Full Manual. Version 3.2. Department of Medical Physics and Biomedical Engineering, Salisbury NHS Foundation Trust, Salisbury, UK, 2002.

39 Grossman W. Diastolic dysfunction and congestive heart failure. Circulation 1990; 81: $1-7$.

40 Packer M. Abnormalities of diastolic function as a potential cause of exercise intolerance in chronic heart failure. Circulation 1990; 81: 78-86.

41 Lorell BH, Blasé A, Carabello A. Left ventricular hypertrophy. Circulation 2000; 102 : $470-479$. 
42 Houtman S, Oeseburg B, Hopman MT. Blood volume and haemoglobin after spinal cord injury. Am J Phys Med Rehabil 2000; 79: 260-265.

43 Krassioukov A, Eng JJ, Warburton DE, Teasell R, Spinal Cord Injury Rehabilitation Evidence Research Team. A systematic review of the management of orthostatic hypotension after spinal cord injury. Arch Phys Med Rehabil 2009; 90: 876-885.

44 Aslan SC, Randall DC, Donohue KD, Knapp CF, Patwardhan AR, Mc Dowell SM et al. Blood pressure regulation in neutrally intact human vs. acutely injured paraplegic and tetraplegic patients during passive tilt. Am J Physiol Regul Integr Comp Physiol 2007; 292: $1146-1157$.

45 Reckelhoff JF. Gender differences in the regulation of blood pressure. Hypertension 2001; 37: 1199-1208.
46 Hettinga DM, Andrews BJ. Oxygen consumption during functional electrical stimulation-assisted exercise in persons with spinal cord injury. Sports Med 2008; 38 825-838.

47 Scharhag J, Schneider G, Urhausen A, Rochette V, Kramann B, Kindermann W. Athletes heart: right and left ventricular mass and function in male endurance athletes and untrained individuals determined by magnetic resonance imaging. J Am Coll Cardiol 2002; 40: 1856-1863.

48 Takahashi M, Matsukawa K, Nakamoto T, Tsuchimochi H, Sakaguchi A, Kawaguchi K et al. Control of heart rate variability by cardiac parasympathetic nerve activity during voluntary static exercise in humans with tetraplegia. J Appl Physiol 2007; 103. 1669-1677. 